\title{
CIHR reforms contradict consultant reports
}

$\mathrm{R}$ eforms to the longstanding scientific advisory system at the Canadian Institutes of Health Research (CIHR) are under attack from a high-profile group of the institute's leading scientific advisors. CIHR is kneecapping its scientific outreach capabilities, these advisors say. And in doing so, they add, CIHR has ignored warnings and advice from the two expert panels it convened to lead scientific consultations on its reforms.

The reforms will reduce the number of institute advisory boards (IABs) serving CIHR's 13 health research institutes from 13 to 4; each of these 4 boards will be assigned to 3 or 4 institutes. This will result in a dramatic narrowing of CIHR's access to specialist, scientific guidance, according to the chairs of five of the current IABs.

As evidence of this contention, they point to a pair of reports presented last spring to the CIHR from two panels of internal and external experts. Both reports caution the CIHR against sudden changes while urging it to broaden its scientific outreach.

The panels were convened by CIHR to "demonstrate greater accountability and results to taxpayers and stakeholders" by conducting "an extensive consultative process both within Canada and internationally" before launching reforms to funding and governance.

The reports on this consultation process were released by CIHR to CMAJ on Dec. 9 following sustained pressure from several IAB chairs who charged CIHR with refusing to fully disclose the reasons behind its reforms.

Although both reports delineate the CIHR's reform options, neither recommends CIHR reduce the number of its scientific advisory boards, says Dr. Andreas Laupacis, executive director of the Li Ka Shing Knowledge Institute at Toronto's St. Michael's Hospital and chair of the IAB for CIHR's Institute of Health Services and Policy Research.

"There was a suggestion that the membership of some IABs might change," says Laupacis, "but nothing else beyond that."

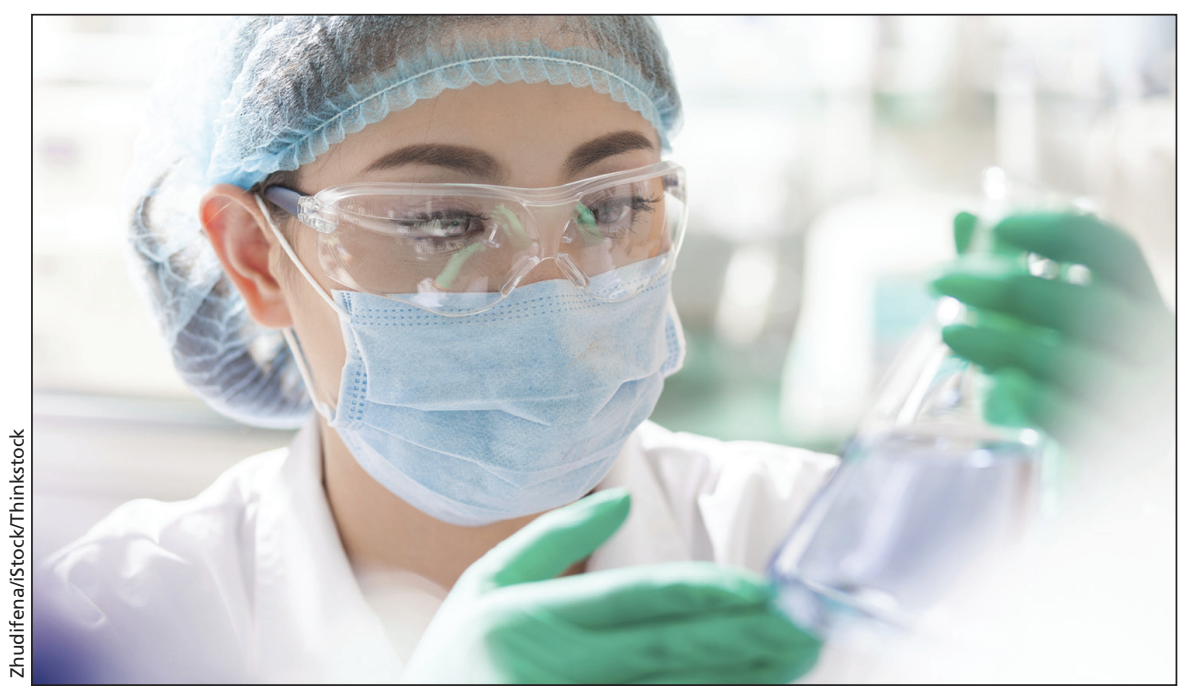

CIHR plans to cut its advisory boards from 13 to 4 despite expert advice.

Dr. Anthony Jevnikar, professor of medicine, microbiology and immunology at Western University in London, Ontario, who chairs the IAB for the CIHR Institute of Infection and Immunity, likewise noted that neither expert panel recommended CIHR reduce the number of IABs. Jevnikar and four other chairs of IABs have written to CIHR President Dr. Alain Beaudet criticizing the changes to the IAB structure.

"It appears that the proposed changes are bent on reducing CIHR to a small number of functional units, with overly broad missions and weak connections to the scientific community," says Dr. Stephanie Atkinson, a professor of pediatrics at McMaster University who chairs the IAB for the CIHR's Institute of Nutrition, Metabolism and Diabetes.

CIHR's Governing Council was actually advised by its Internal Working Group panel to expand its pool of scientific advisors, Atkinson says.

In recommending CIHR foster greater collaboration among its institutes, she says, the internal consulting panel warned CIHR against dramatic changes to the institutes. According to the report, the "IABs were thought to be an important means to provide advice on the institutes' direction, and the expertise, experiences and passion of the members of the IABs should be better leveraged. ... The composition of IABs should be reviewed and possibly expanded to include a broader range of non-science based members."

Although the panel also recommended "the Institutes should be much more involved in outreach efforts to all stakeholders," Atkinson says, "this will be impossible to achieve with contraction of the number of IAB members."

"I cannot honestly find convincing evidence in any of the recommendations from either report to substantiate the directives that have been mandated," says Atkinson. "In some cases, the directives appear to be exactly contrary to the recommendations.'

For its part, the CIHR told CMAJ in a written statement, that its decision to create a smaller number of IABs shared by several institutes "will enhance collaboration across research pillars, disciplines, and communities while decreasing administrative burden."

CIHR spokesman David Coulombe stated in an email that in the face of its consultation reports, "Ultimately, it was the responsibility of Governing Council to decide on any potential changes to the model, role and slate of the Institutes based on their own deliberations."

CIHR declined an interview request from CMAJ. — Paul Webster, Toronto, Ont.

CMAJ 2015. DOI:10.1503/cmaj.109-4963 